\title{
A Comparison of Three Methods for Measuring Local Urban Tree Canopy Cover
}

\author{
Kristen L. King and Dexter H. Locke
}

\begin{abstract}
Measurements of urban tree canopy cover are crucial for managing urban forests and required for the quantification of the benefits provided by trees. These types of data are increasingly used to secure funding and justify large-scale planting programs in urban areas. Comparisons of tree canopy measurement methods have been conducted before, but a rapidly evolving set of new technologies and applications may leave urban foresters wondering, "Which method is most appropriate for my circumstances?" This analysis compares two well-established measures of local tree canopy and building cover with a third, relatively untested technique. Field-based visual estimations (using the USDA Forest Service's i-Tree protocols), summaries of highresolution land cover data using geographic information systems (GIS), and an analysis of skyward-oriented hemispherical photographs at 215 roadside sites across the five diverse counties of New York City, New York, U.S., are the methods evaluated herein. The study authors found no statistically significant differences between the methods when comparing tree canopy; however, the hemispherical camera had a tendency to overestimate building coverage. It is concluded that hemispheric photo techniques are understudied in urban areas, and that the i-Tree and GIS-based approaches are complementary and reinforcing tools indispensable for both the urban forest management and research communities.

Key Words. Forest Measurement; Gap Light Analyzer; GIS; Hemispheric Photos; i-Tree; Urban Land Cover; Urban Tree Canopy.
\end{abstract}

Measurements of urban tree canopy cover are crucial for managing urban forests and required for the quantification of the benefits provided by trees. These types of data are increasingly used to secure funding or justify large-scale planting programs in urban areas. Although many municipalities undertake these types of analyses, there are multiple methods for doing so (Nowak et al. 1996), and given different available technologies and underlying assumptions, these tools will ultimately differ in their results and costs. Comparisons of canopy cover measurement methodologies in undeveloped areas are quite common (e.g., Ganey and Block 1994; Fiala et al. 2006), and previous research has compared other methods of calculating urban tree cover (Nowak et al. 1996). But with the advent of new technologies and applications this problem is worth revisiting. This analysis compares three measures of local tree canopy and building cover derived from fieldbased visual estimations, summaries of very high-resolution land cover data using geographic information systems (GIS), and an analysis of skyward-oriented hemispherical photographs at 215 sites across the five counties of New York City, New York, U.S.

\section{MATERIALS AND METHODS}

The majority of data (155 of 215 total sites) for this analysis were collected in 2009 in support of the New York City Community Air Survey (NYCCAS). Of the 155 air quality monitoring sites, 120 were preferentially assigned to areas with high traffic density, high building density, or both. Because of this stratified random sampling, plots represent a broad geographical range and diverse urban conditions while maintaining a sufficiently robust sample size (Figure 1). An additional 60 sites featured the same measurements in a more restricted area of New York City (including the northern Manhattan and Bronx boroughs, or administrative divisions) and these data were collected as part of a separate air quality study during the summer of 2010 . Because of this, sampling intensity is greater in that geographic area.

Two field-based measures of local tree canopy were taken at all 215 sites. Estimates of tree canopy and building coverage were collected in accordance with the USDA Forest Service's Urban Forest Effects Model (UFORE) protocol, now called i-Tree Eco (see USDA Forest Service's i-Tree Eco User's Manual for additional details), within 0.08 ha circular plots surrounding street-side utility poles, which functioned as the plot's center. The goals of the NYCCAS study, for which these data were originally intended, required that 0.08 ha plots were used instead of the smaller, standard 0.04 ha. Tree cover, as the amount of the plot covered by tree canopy, is gathered by visualizing the area of the plot that would be shaded by trees when the sun is directly overhead, ranging from $0 \%$ to $100 \%$, in $5 \%$ increments. When trace amounts are present, $1 \%, 2 \%, 3 \%$, etc., are recorded. Canopy from trees outside of the plot are included, so plots not actually containing trees can have measurable tree cover. Aerial images were used to assist the field crew's estimations. Using the same incremental measurements, building coverage is determined by estimating what portion of the plot ground area is covered by 


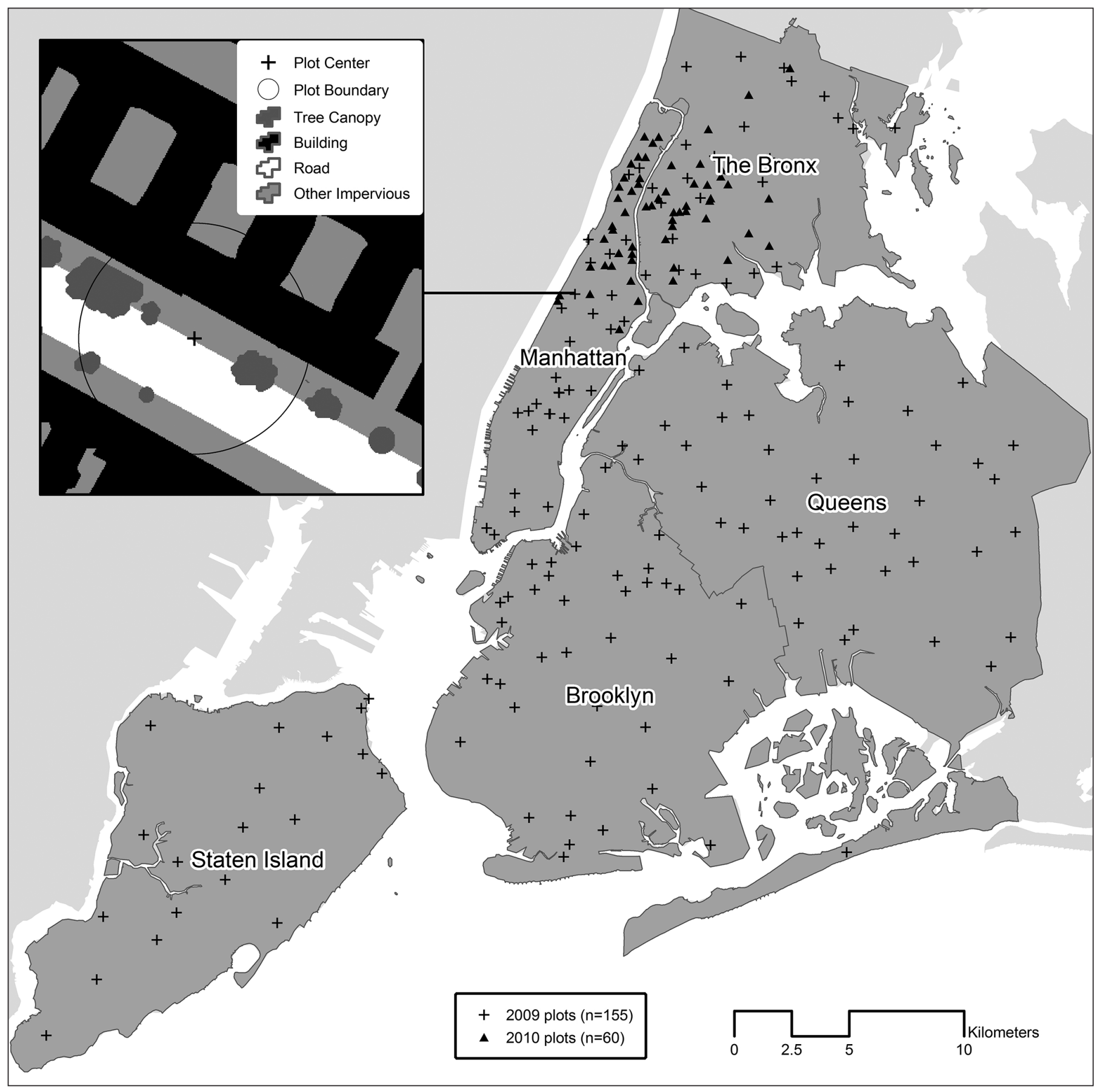

Figure 1. Geographic range of local urban tree canopy sampling plots in New York City. Inset: GIS-based analysis of field-measured plots using high-resolution land cover data.

a building's footprint. Tree canopy and ground cover (which includes buildings) are considered different urban forest strata when using the i-Tree methods and are thus not mutually exclusive. In other words, when canopy overhangs a building, both are measured independently; this is an important difference compared to the land cover summary method to be discussed later.

At the center of each 0.08 ha plot, a hemispheric photo was also taken at a height of approximately five feet using a Nikon COOLPIX 4300 camera in year one and a Panasonic DMC-FZ35 camera in year two, along with a 183-degree fisheye lens [Nikon
Fisheye Converter in year one and Raynox DCR-CF187PRO with Panasonic conversion lens adapter (f/dmc-fz18 reg) in year two]. The resultant photos were analyzed using the free Gap Light Analyzer (GLA) software to calculate percent canopy and percent building cover. In brief, the GLA analysis process was as follows: after calculating the percentage of the circular photo that was only sky in a saturated photograph (\% sky view; not building, tree, or other item), any trees were manually removed from the image and the percent sky recalculated with the trees removed (Gordon Heisler, pers. comm. July 2009). See Frazer et al. (1999) 
for additional details on the software package. The difference between the whole percent sky view and the sky view without trees is the percent tree canopy cover (Figure 2). Subtracting percent sky view without trees from $100 \%$ yields percent building cover. When tree crown overlaps with building, the blockage was considered to be by the building. Both percent tree canopy cover and percent building cover calculations are continuous values.

Tree canopy and building cover were also enumerated within each of the 215 plots using a top-down GIS-based analysis derived from a $15.24 \mathrm{~cm}$ resolution seven-class land cover map. The seven classes are tree canopy, grass/shrub, bare earth, water, buildings, roads, and other paved surfaces. Each class is mutually exclusive and tree canopy that hangs over buildings are assigned to the tree class. The primary sources used to derive this land cover layer were a LiDAR point cloud acquired in 2010 and a 4-band orthoimagery data set collected in 2008. Ancillary data sources included GIS data (city boundary, building footprints, water, parking lots, roads, railroads, railroad structures, ball fields) provided by the City of New York. Object-based image analysis techniques were employed to extract land cover information from these combined datasets by grouping pixels into meaningful objects based on their spectral and spatial properties, while taking into account boundaries imposed by existing vector data sets. More than 35,000 corrections were made to the classification.
Overall accuracy exceeds $96 \%$, kappa $=0.95$ (MacFaden et al. 2012). These data represent the most comprehensive and accurate land cover depiction of the study area ever created. From this detailed map, the continuous percentage of each 0.08 ha plot composed of tree canopy and building footprint were calculated using the Tabulate Area tool in ArcGIS 10.

Percent tree canopy and building cover for all three methods were compared using the Friedman test, a nonparametric analog of the two-way ANOVA. All statistical analyses were performed in PASW Statistics 18.0 (IBM).

\section{RESULTS AND DISCUSSION}

For measurements of local urban tree canopy cover, field-based i-Tree Eco data collection and hemispheric photo analysis with GLA software do not differ significantly from each other or from the GIS-based method (Table 1). The relative rankings in the Friedman test for building cover indicate that using hemispheric photos for measuring building cover in urban environments results in systematically higher measurements of this variable than the other two methods, which is a significant difference (Table 1). Comparison of the i-Tree- and GIS-based methods reveals that they are not significantly different from each other (Mann-Whitney $\mathrm{U}=21329 ; \mathrm{p}=0.160$ ), although this field measurement provided slightly higher estimates (Figure 3).

\section{Original fisheye photos used for GLA processing}
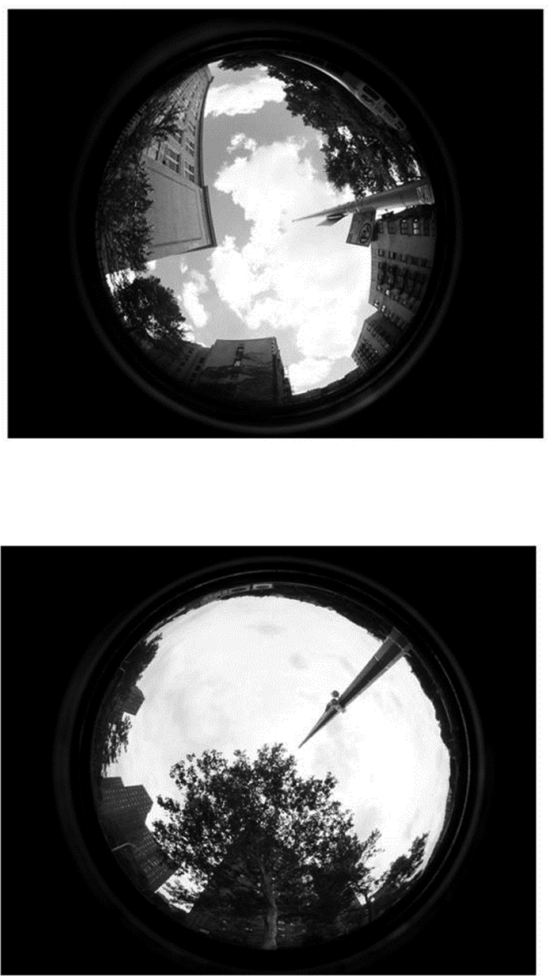

\section{Processed images}

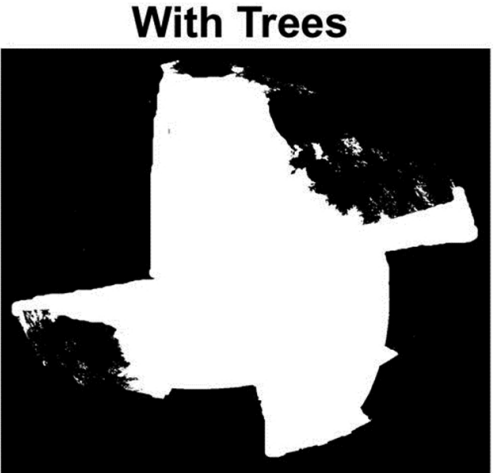

With trees - $51 \%$ sky view

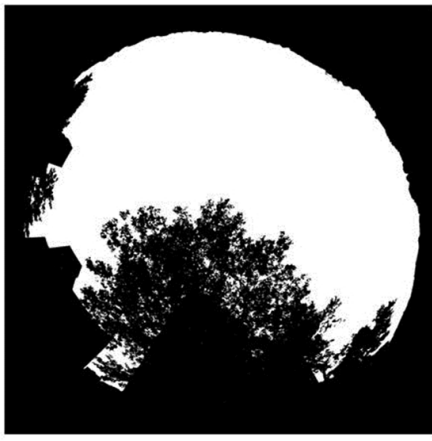

With trees - 54\% sky view

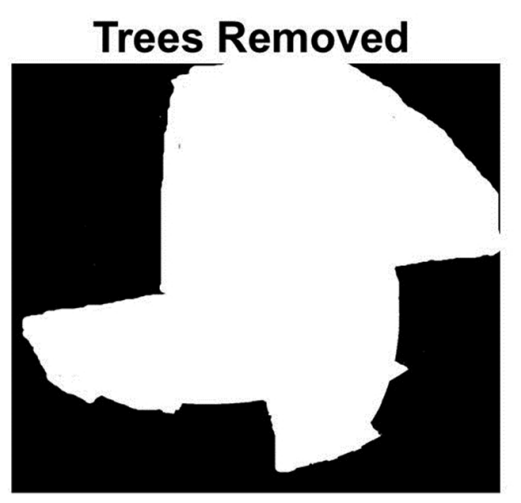

Trees removed - 67\% sky view $\%$ tree canopy cover $=16 \%$

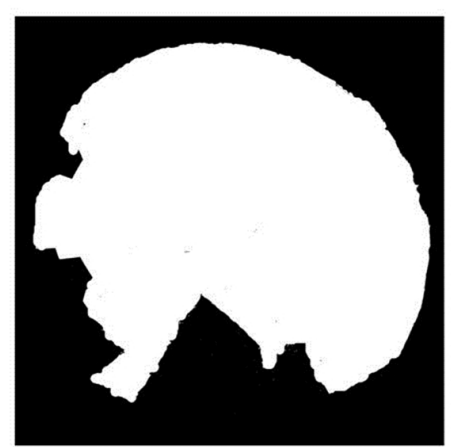

Trees removed $-72 \%$ sky view $\%$ tree canopy cover $=18 \%$

Figure 2. Processing of urban tree canopy hemispheric photos using Gap Light Analysis software. 
Measuring local tree canopy cover across a large urban area with i-Tree, GLA, or high resolution land cover maps yields similar results when examining circular roadside plots. This has important implications for urban forestry programs that may have limited funds or do not have access to hemispheric photography equipment or technologically advanced remote sensing techniques. In situ human visual estimation of tree canopy cover aided by aerial imagery in a 0.08 ha circular plot using a protocol such as i-Tree Eco is just as effective as these more sophisticated methodologies. However, collecting hemispheric photographs may be faster than i-Tree Eco's complete plot sampling routine. Therefore, if only tree canopy

Table 1. Friedman test results for the comparison of local urban tree canopy measurement methodologies.

\begin{tabular}{|c|c|c|c|c|c|c|}
\hline \multirow[t]{2}{*}{ Measurement } & \multirow[t]{2}{*}{ Method } & \multirow[t]{2}{*}{ Mean rank } & \multicolumn{4}{|c|}{ Test statistics } \\
\hline & & & $\mathrm{N}$ & $\chi$-square & $\mathrm{df}$ & Significance \\
\hline Tree canopy & $\begin{array}{l}\text { i-Tree } \\
\text { GIS } \\
\text { GLA }\end{array}$ & $\begin{array}{l}2.07 \\
1.94 \\
1.98\end{array}$ & 215 & 1.956 & 2 & 0.376 \\
\hline $\begin{array}{l}\text { Building } \\
\text { cover }\end{array}$ & $\begin{array}{l}\text { i-Tree } \\
\text { GIS } \\
\text { GLA }\end{array}$ & $\begin{array}{l}1.80 \\
1.42 \\
2.79\end{array}$ & 215 & 250.663 & 2 & $<0.0001$ \\
\hline
\end{tabular}

were of interest one could presumably increase sampling intensity using the GLA method. Further work is needed to confirm.

An earlier unpublished comparison of these field measures of urban tree canopy with measures derived from a 2001 land cover map made using EMERGE imagery (Myeong et al. 2001; USDA Forest Service 2002) did not show the same agreement; the lower-quality remotely sensed data had a tendency to underestimate tree canopy cover across the urban landscape largely attributable to the shading out of vegetation by tall buildings and other obstructions within the urban canyon. This type of underestimation is associated with remote sensing that utilizes a passive sensor rather than an active one, such as LiDAR. Passive sensors receive solar reflectance off the earth's surfaces, leaving shaded areas difficult to discern. LiDAR sensors emit their own energy and can therefore effectively "see through" shadows. Not all remotely sensed data are created equal; the agreement between the 2010 map and field-based measures is likely due to the extremely high quality and resolution of that land cover data.

More than four dozen urban tree canopy reports, mostly conducted in the northeastern United States, show that urban vegetation is often most located within private residential properties, and that much of the opportunities for further increases in tree canopy are also on private residential sites (see http:// nrs.fs.fed.us/urban/utc/pubs/). The sampling strategy employed

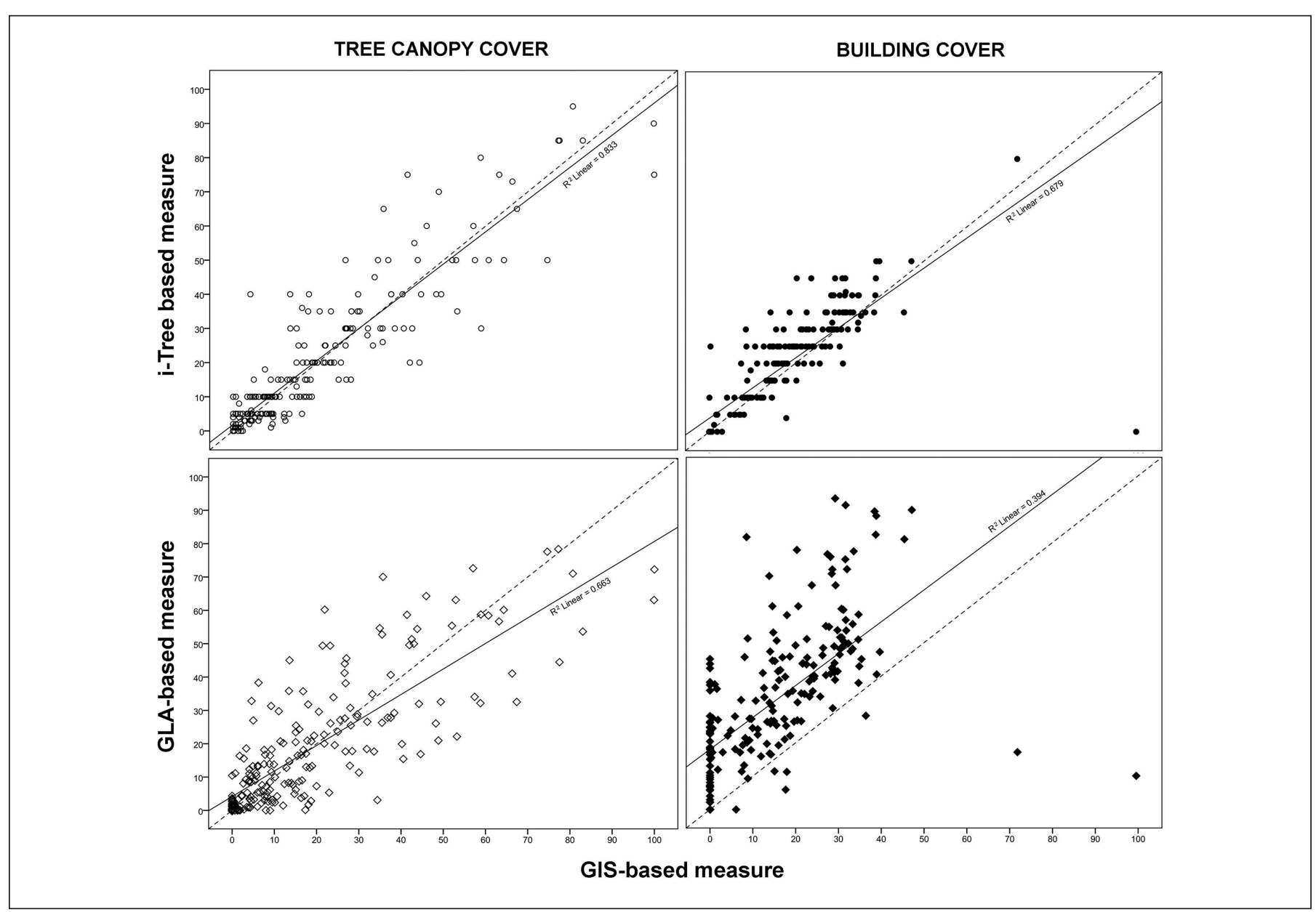

Figure 3. Comparison of field-taken tree canopy and building cover measures with the GIS-based measure. Dashed lines represent a perfect 1:1 correspondence of the two measures; solid line is the actual fit of the data. 
in this study misses much of this critical resource due to the roadside nature of the sampling locations. For estimates of localized building cover, the GLA methodology results in higher values than the other two methods. If the $15.24 \mathrm{~cm}$ land cover data and derived GIS-based measurement may be considered the baseline due to its high spatial resolution and categorical accuracy, then the GLA-based method overestimates building cover - likely because the hemispheric photos are capable of capturing buildings outside the reaches of the 0.08 ha plot. Furthermore, near and tall objects such as buildings may dominate the field of view. To the knowledge of the authors, this study represents the first use of the GLA methodology and software within an urban setting for the purpose of enumerating tree and building cover, and although the method was acceptable for measuring local tree canopy cover, it is not advised that researchers use these methods for capturing building cover across an urban landscape.

Intensive field-based methods, such as i-Tree and GLA, involve direct sampling, while the extensive GIS-based approach utilizes a census of land cover derived from remotely-sensed data. Each method has value outside of simple measurements of urban tree canopy cover. Other data collected when using the standard i-Tree methods can be used to model ecosystem service values. GLA data may provide further analytical possibilities, including urban micro-meteorological modeling and human comfort analyses (i.e., Heisler et al. 2003; Heithecker and Halpern 2006). In addition to quantifying tree canopy and building cover, the GIS-based approach can also be used to analyze patterns in the urban landscape or identify possible planting areas by enumerating the amount of vegetated, soil, and impervious areas that are not buildings, roads, water, and existing trees within any ecological or administrative boundaries. The high spatial resolution $(15.24 \mathrm{~cm})$ also allows for parcel-scale analyses, which are important because households may be considered the fundamental decision-making unit in urban areas (Pickett et al 2011). Researchers conclude that GLA techniques are understudied in urban areas, and that the i-Tree and GIS-based approaches are complementary and reinforcing tools indispensable for both the urban forest management and research communities.

Acknowledgements. The authors thank the USDA Forest Service, Northern Research Station, Dr. Lynne Westphal, Dr. Gordon Heisler, and the National Urban and Community Forestry Advisory Council. Additionally, this work benefited from Kyle Kalwarski, Jacqueline W.T. Lu, Nancy Falxa-Raymond, Peter Tiso, Peter Stothart, Sharai Lewis-Gruss, and Rich Hallett.

\section{LITERATURE CITED}

Fiala, A.C.S., S.L. Garman, and A.N. Gray. 2006. Comparison of Five Canopy Cover Estimation Techniques in the Western Oregon Cascades. Forest Ecology and Management 232:188-197.

Frazer, G.W., C.D. Canham, and K.P. Lertzman. 1999. Gap Light Analyzer (GLA), Version 2.0: Imaging software to extract canopy structure and gap light transmission indices from true-colour fisheye photographs, users' manual and program documentation. Simon Fraser University, Burnaby, British Columbia, and the Institute of Ecosystem Studies, Millbrook, New York, U.S.

Ganey, J.L., and W.M. Block. 1994. A Comparison of two techniques for measuring canopy closure. Western Journal of Applied Forestry 9:21-23.

Heisler, G.M., R.H. Grant, D.J. Nowak, Wei Gao, D.E. Crane, J.T. Walton. 2003. Inclusion of an ultraviolet radiation transfer component in an urban forest effects model for predicting tree influences on potential below-canopy exposure to UVB radiation. In: J.R. Slusser, J.R. Herman, and Wei Gao (Eds.). Proceedings of SPIE Vol. 5156 Ultraviolet Ground- and Space-based Measurements, Models, and Effects III. SPIE: Bellingham, Washington, U.S.

Heithecker, T.D., and C.B. Halpern. 2006. Variation in microclimate associated with dispersed-retention harvests in coniferous forests of western Washington. Forest Ecology and Management 226:60-71.

MacFaden, S.W., J.P.M. O'Neil-Dunne, A.R. Royar, J.W.T. Lu, and A.G. Rundel 2012. High-resolution Tree Canopy Mapping for New York City using LiDAR and Object-based Image Analysis. Journal of Applied Remote Sensing.

Myeong, S., D.J. Nowak, P.F. Hopkins, and R.H. Brock. 2001. Urban Cover Mapping Using Digital, High-spatial Resolution Aerial Imagery. Urban Ecosystems 5:243-256.

Nowak, D.J., R.A. Rowntree, E.G. McPherson, S.M. Sisinni, E.R. Kerkmann, and J.C. Stevens. 1996. Measuring and Analyzing Urban Tree Cover. Landscape and Urban Planning 36:49-57.

Pickett, S.T.A., M.L. Cadenasso, J.M. Grove, C.G. Boone, P.M. Groffman, E. Irwin, S.S. Kaushal, et al. 2011. Urban Ecological Systems: Scientific Foundations and a Decade of Progress. Journal of Environmental Management 92(3):331-362.

The City of New York, Mayor Michael R. Bloomberg. 2007. PlaNYC: A Greener, Greater New York. <www.nyc.gov/html/planyc2030/ $\mathrm{html} /$ theplan/the-plan.shtml>

USDA Forest Service. 2002. High resolution 2001/2002 land cover data for New York City.

USDA Forest Service. i-Tree Eco User's Manual. Accessed 03/30/2012. $<$ www.itreetools.org/resources/manuals/i-Tree\%20Eco $\% 20$ Users\%20Manual.pdf>

Kristen L. King (corresponding author)

New York City Department of Parks and Recreation

Forestry, Horticulture, and Natural Resources Group

1234 Fifth Avenue

New York, New York 10029, U.S.

kristen.king@parks.nyc.gov

Dexter H. Locke

NYC Urban Field Station

431 Walter Reed Road

Fort Totten Park

Bayside, New York 11360, U.S.

dexter.locke@gmail.com 
Zusammenfassung. Messungen der urbanen Baumkronenbedeckung sind erforderlich für das Management von urbanen Forstflächen und für die Quantifizierung der Vorteile eines Baumbestandes. Dieser Typ von Daten wird zunehmend verwendet, um Mittel zu sichern und groß angelegte Pflanzungen in urbanen Regionen zu rechtfertigen. Der Vergleich von Messmethoden zur Baumkronenbedeckung wurde bereits durchgeführt, aber ein sich schnell entwickelndes Angebot an neuen Technologien und Anwendungen lässt viele urbane Forstleute fragen: ,Welche Methode ist für meine Umstände die passende Methode?'

Diese Analyse vergleicht zwei gut etablierte Messmethoden der Baumbedeckung und Versiegelung durch Gebäude mit einer dritten, relativ ungetesteten Methode. Feld-basierende visuelle Schätzungen (unter Verwendung des USDA Forstservice i-Tree Protokolls), Zusammenfassungen von hoch aufgelösten Landbedeckungsdaten auf GIS-Basis und eine Analyse von himmelwärts orientierten Hemisphärischen Fotographien an 215 Straßenstandorten in fünf verschiedenen Regionen in New York City, New York, U.S. wurden als zu bewertende Methoden verwendet.

Die Autoren der Studie fanden keine statistisch signifikanten Unterschiede innerhalb der Methoden, wenn die Baumbedeckung verglichen wurde, allerdings hatte die hemisphärische Kamera die Tendenz, die Bedeckung mit Gebäuden zu überschätzen.

Es ist herausgekommen, dass hemisphärische Fototechniken in urbanen Regionen noch wenig getestet sind und dass die auf i-Tree und GIS basierenden Anwendungen ergänzende und verstärkende Werkzeuge für das urbane Forstmanagement und die Forschungsgemeinde darstellen.

Resumen. Las mediciones de la cobertura de los árboles urbanos son cruciales para la gestión de los bosques urbanos y necesarios para la cuantificación de los beneficios proporcionados por los árboles. Estos tipos de datos se utilizan cada vez más para asegurar la financiación y justificar grandes programas de plantación en las zonas urbanas. Las comparaciones de los métodos de medición de árboles del dosel se han realizado antes; sin embargo, la rápida evolución de las nuevas tecnologías y aplicaciones pueden dejar a los forestales urbanos preguntando: "¿Qué método es más adecuado para mi situación?"

Este análisis compara dos medidas bien establecidas de copas de los árboles y la cubierta local de edificios con una tercera técnica, relativamente no probada. Las estimaciones visuales de campo (utilizando el protocolo i-Tree del Servicio Forestal USDA), resume los datos de alta resolución de cobertura de la tierra mediante sistemas de información geográfica (SIG) y un análisis de fotografías hemisféricas orientadas en 215 sitios en la carretera a través de cinco condados diversos de New York City, Nueva York, EE.UU. Estos son los métodos evaluados en este documento.

Los autores del estudio no encontraron diferencias estadísticamente significativas entre los métodos cuando se comparan copas de los árboles; sin embargo, la cámara hemisférica tenía una tendencia a sobreestimar la cobertura del edificio

Se concluye que las técnicas hemisféricas de foto aún son poco estudiadas en las zonas urbanas, y que los métodos i-Tree y con base en SIG son herramientas complementarias y se refuerzan tanto para la gestión de los bosques urbanos y comunidades de investigación. 